\title{
Rely to Professor Allen
}

\author{
George Bowles
}

Abstract: I reply to three criticisms of my "Propositional Relevance" offered by Derek Allen. First, Professor Allen points out an inconsistency between my theory of relevance and my reply to an objection. I admit the error but add that it is remediable. Second, he argues that my theory of relevance is counterintuitive. I argue that it is not. And finally, he says that where I use phrases like ' $p$ makes $q$ certain,' I should instead use phrases like ' $p$, if true, makes $q$ certain.' I argue against this.
Résumé: Je réplique aux trois objections du Professeur Derek Allen contre mon article, "Propositional Relevance." Premièrement, il relève une incohérence entre ma théorie de la pertinence et ma réplique contre une objection. Je reconnais l'erreur, mais elle est remédiable. Deuxièment, il soutient que ma théorie de la pertinence va contre le bons sens. Jemaintiens que ce n'est pas le cas. Enfin, il croit qu'au lieu d'employer des phrases telles que $p$ rend $q$ certaine, je devrais utiliser $p$, si elle est vraie, rend $q$ certaine. J'argumente contre cette suggestion.

In his perceptive article "Relevance, Conduction and Canada"s Rape-Shield Decision" (Informal Logic, XV.2 [Spring 1993], 105-122), Derek Allen offers three criticisms of my "Propositional Relevance" (Informal Logic, XII.2 [Spring 1990], 65-77), to which I would like to reply.

Criticism 1. On page 115 Professor Allen points out an inconsistency between my theory of relevance and my reply to Objection $8(72)$. He observes that the former, but not the latter, would permit a conjunction at least one of whose conjuncts was false to be relevant to another proposition.

Reply. I acknowledge the error and thank Professor Allen for pointing it out. My reply to Objection 8 should be revised along the lines of the Reply to Criticism 2, below, to make it consistent with my theory.

Criticism 2. Professor Allen says that my theory of relevance is counterintuitive when applied to Trudy Govier's aspirin example (presented in my paper in Objection 8), since it leads to the conclusion that ' $p$ ', 'Aspirin tends to cause stomach bleeding', is not favorably relevant to ' $q$ ', 'You shouldn't take aspirin unless you really need it'.

But that $(p)$ is not (positively) relevant to $(q)$ is counterintuitive. For it is intuitively very plausible both that $(p)$ is relevant to $(q)$ if $(p)$ is a reason for $(q)$ and that $(p)$ is a reason for $(q)$-that 1 am given a reason not to take aspirin unless $I$ really need it if I am informed that aspirin tends to cause stomach bleeding. Hence it is intuitively very plausible that $(p)$ is relevant to $(q)$. (116)

Reply. The issue is whether ' $p$ ' alone, not conjoined with any third proposition, is a reason for ' $q$ '. I do not find it as intuitively plausible as do Professors Allen and 


\section{George Bowles}

Govier that ' $p$ ' alone is a reason for ' $q$ '. My reasons are two. (1) Let an argument's one premise be ' $p$ ', 'Aspirin tends to cause stomach bleeding', and its conclusion be ' $q$ ', 'You shouldn't take aspirin unless you really need it'. This argument is bad: ' $p$ ' is not a reason, or at least not a good reason, for ' $q$ '. If it is given only that aspirin tends to cause stomach bleeding, but not whether we should not take anything that tends to cause stomach bleeding unless we really need it, we can reach no conclusion about whether we should not take aspirin unless we really need it. For the conclusion, ' $q$ ', is an 'ought'-proposition ('shouldn't'), whereas the premise, ' $p$ ', is an 'is'-proposition; and an 'is'-proposition alone is not a (good) reason for an 'ought'-proposition. In order to be good, then, the argument requires an 'ought'-proposition as another premise. And because the given premise, but not the conclusion, deals with something's tending to cause stomach bleeding, the missing premise deals with something's tending to cause stomach bleeding. Moreover, since the conclusion says that we should not do what the given premise says tends to cause stomach bleeding, the missing premise says not that we ought to do what tends to cause stomach bleeding, but that we ought not. So, the missing premise says at least something like, 'You shouldn't take anything that tends to cause stomach bleeding'. Furthermore, because the conclusion adds the exception, 'unless you really need it', which is absent from the given premise, the same exception is in the missing premise. That premise, then, is, or at least resembles, ' $r$ ', 'You shouldn't take anything that tends to cause stomach bleeding unless you really need it'.

The foregoing is an extended explanation of something about the argument from ' $p$ ' to ' $q$ ' that would probably seem clear even to beginning students-namely, that it assumes an additional premise like ' $r$ '. But, if it is intuitively plausible that ' $p$ ' alone is a reason for ' $q$ ', why is it also so clear that the argument from ' $p$ ' to ' $q$ ' assumes an additional premise like ' $r$ '?

(2) Suppose that ' $p$ ' alone, not conjoined with any other proposition, is a reason for ' $q$ '. Now, if ' $p$ ' were conjoined with another proposition, ' $s$ ', which, by itself, is not a reason for or against ' $q$ ', it is intuitively plausible that the conjunction " $p$ " and " $s$ "' would not be a reason against ' $q$ '. (For instance, 'Most dogs have fleas' is a reason for 'My dog has fleas". So, if 'Most dogs have fleas' were conjoined with a proposition that, like 'Most cats have worms', is not a reason for or against 'My dog has fleas', then the conjunction 'Most dogs have fleas and most cats have worms' would not be a reason against 'My dog has fleas'.) Yet when ' $p$ ' is conjoined with ' $s$ ', 'You should take whatever tends to cause stomach bleeding even if you don't really need it', which alone is not a reason for or against ' $q$ ', the conjunction is a reason against ' $q$ '. Therefore, ' $p$ ' alone is not a reason for ' $q$ '.

For these two reasons, I conclude that ' $p$ ' alone is not a reason for ' $q$ '. The fact that the two propositions share subject matter does not suffice to make one a reason for the other. And the fact that the conjunction " $p$ " and " $r$ "' is a reason for ' $q$ ' does not mean that either conjunct alone is a reason for ' $q$ ', since otherwise 'Some sheep are black' would be a reason for 'You shouldn't take aspirin unless you really need it', because the conjunction 'Some sheep are black and you shouldn't take anything unless you really need it' is.

Criticism 3. Professor Allen says that where I use the phrases " $p$ " makes " $q$ " 
certain' and " $p$ " makes " $q$ " probable', I should instead use the phrases " $p$ ", if true, makes " $q$ " certain' and ' " $p$ ", if true, makes " $q$ " probable'. He reasons:

Bowles says: "' $p$ ' makes ' $q$ ' certain if and only if the probability of ' $q$ ' conditional on ' $p$ ' is 1 ", and " $p$ ' makes ' $q$ ' probable if and only if the probability of ' $q$ ' conditional on ' $p$ ' is less than 1 but greater than $1 / 2$ "... If so, then ' $p$ ' need not be true to make ' $q$ ' certain or probable. I disagree, in the belief that a false proposition cannot make another proposition probably true or certainly true. If so, then ' $p$ ' may not make ' $q$ ' certain even if the probability of ' $q$ ' conditional on ' $p$ ' is 1 , and ' $p$ ' may not make ' $q$ ' probable even if the probability of ' $q$ ' conditional on ' $p$ ' is less than 1 but greater than $1 / 2 \ldots(121$, n. 14)

Reply. This argument depends on the premise that a false proposition cannot make another proposition probably true (probable) or certainly true (certain). But this premise seems false, for two reasons. (1) Intuitively, it seems, first, that the proposition, 'I reside in North America' is made probable by the false proposition, 'Most people reside in North America' (i.e., the former proposition is probable relative to the latter); and, second, that the same proposition is made certain by the false proposition, 'Everyone resides in North America' (i.e., the former proposition is certain relative to the

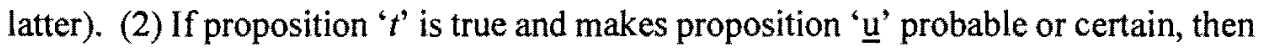
so does the false conjunction of ' $t$ ' with any proposition inconsistent with ' $t$ ' or, indeed, with any false proposition. It is, then, possible for a false proposition to make another proposition probable or certain.

\section{Notes}

'Since ' $q$ ' is about whether you should take aspirin, whereas 's' says nothing about aspirin, there should be little temptation to think that ' $s$ ' alone is reason for or against ' $q$ '. Although ' $q$ ' and ' $s$ ' share some content (both are 'ought'-propositions and both deal with taking something that tends to cause stomach bleeding), that alone does not mean that ' $s$ ' is a reason for or against ' $q$ '. If it did, 'At least one tiger is not a native of Greenland' would be a reason for or against 'At least one tiger is a native of Greenland'.

GEORGE BOWLES ARLINGTON, VIRGINIA 